\title{
Thymic T-Cell Selection
}

National Cancer Institute

\section{Source}

National Cancer Institute. Thymic T-Cell Selection. NCI Thesaurus. Code C19064.

Bone marrow-derived stem cells in the thymus become educated to recognize complexes of self-major histocompatibility complex (MHC) molecules plus self-peptides in a process called positive selection under the influence of epithelial cells in the thymic cortex. Positively-selected thymic T cell precursors (thymocytes) then progress through a process called neg ative selection under the influence of bone marrow-derived dendritic cells at the corticomedullary junction where self-reactive, and potentially autoimmunityinducing, thymocytes are deleted. Thymocytes simultaneously progress through phases expressing both CD4 and CD8 coreceptors to a single positive stage expressing only CD4 or CD8 in addition to the T cell receptor. They are then allowed to leave the thymus and enter the periphery via the lymphatics or venules of the circulatory system as mature $T$ cells. 